\title{
¿SE NECESITA UNA NUEVA CONSTITUCIÓN EN MÉXICO? ALGUNAS REFLEXIONES Y SEIS PROPUESTAS
}

\author{
DOES MEXICO NEED A NEW CONSTITUTION? \\ SOME REFLECTIONS AND SIX PROPOSALS
}

Jorge CARPIZO*

RESUMEN: En México se expedirá una nueva Constitución cuando la realidad política y la social lo requieran. Sin embargo, por el momento, no es necesario, ya que son más los aspectos negativos y peligrosos que los positivos, situación que nos llevarían a un serio riesgo de retroceso democrático. En todo caso, cuando se llegue el momento de expedir una nueva Constitución, debemos confiar en que se haga por la vía pacífica y como un proyecto pactado entre las principales fuerzas políticas, sometiendo el texto final a un referendo por parte del electorado. La Constitución de 1917 ha sido longeva debido, entre otras razones, a que no se ha dado una ruptura político social, su estructura fundamental ha sido aceptada mayormente por la sociedad, ha sabido evolucionar y cambiar a través de reformas constitucionales, y porque ha impulsado la paz social.

Palabras clave: Nueva Constitución, reforma constitucional, cultura constitucional, referendo constitucional.
ABSTRACT: In Mexico a new constitution shall be issued when political and social realities require. However, for the time being, as the author points, it is no necessary because there are more negatives and dangerous aspects than positives, situation that could take us to a serious risk of democratic regression. At any case, when it is time to issue a new constitution we must trust it will be done by peaceful means and as an agreed project among the main political forces, submitting the final text to a referendum by the electorate. The Mexican Constitution of 1917 has been lasting due to, among other things, a social political brake has not taken place, its fundamental structured has been accepted by society; it has known how to evolve and change through the constitutional amendment and because it has promoted social peace.

Descriptors: New Constitution, constitutional amendment, constitutional culture, constitutional referendum.

* Investigador emérito de la Universidad Nacional Autónoma de México, de la cual fue Rector, adscrito al Instituto de Investigaciones Jurídicas donde se desempeñó como director; presidente del Instituto Iberoamericano de Derecho Constitucional. 


\section{PlanteAmiento DE LA CUESTIÓN}

1. Diversos dirigentes políticos y algunos académicos, ya sea en forma directa o indirecta, han planteado en los últimos años la necesidad y conveniencia de crear una nueva Constitución, y con ese propósito se han convocado foros públicos para analizar esa posibilidad o la de una reforma integral que, en los términos planteados y el número de artículos que se propone reformar, implícitamente resulta en idéntica propuesta que la primera.

Esta cuestión reviste importancia excepcional. El cambio de una Constitución es algo extraordinariamente serio, a grado tal que en muchos países su historia moderna suele estudiarse a través de los lapsos en que estuvo vigente una Constitución, porque ella representa la mejor síntesis política, social, económica y jurídica del país en una época determinada; incluso esa afirmación es válida en Constituciones longevas, a las cuales se las divide en ciclos, sin importar que sean reformadas a través del procedimiento formal o que se actualicen primordialmente a través de los diversos aspectos de la mutación constitucional; por ejemplo, las Constituciones de Estados Unidos, Gran Bretaña o Argentina.

¿En México, ha llegado la hora de transitar a una nueva Constitución?

No lo considero así, porque éste no es un problema teórico o académico, sino de la realidad política y social. Un país hace suya una nueva Constitución cuando tiene que hacerlo, se quiera o no, se considere que el momento es el adecuado o no, y lo mismo va a acontecer en el nuestro: habrá una nueva Constitución cuando la realidad la requiera y la necesidad obligue a ello.

En la actualidad, 2010, no considero que sea la hora de una nueva Constitución, en virtud de que son más los aspectos negativos y peligrosos que los positivos, que se correría el riesgo de más retrocesos democráticos que avances. ¿Y cuándo deberá México contar con una nueva Constitución? Cuando tenga que ser, ¿y cuándo será? Lo desconozco. Vivimos en un país que se encuentra agobiado de problemas por demás graves, con pobreza que agobia a la mitad de la población, desigualdad social insultante, inseguridad pública generalizada, deterioro galopante de los servicios públicos y sociales, millones de jóvenes sin oportunidades de educación o de empleo, corrupción e impunidad desbordadas, moral pública deshecha y escepticismo generalizado. En un Estado en esas condiciones todo puede suceder. Y así se encuentra México. ¿Tendremos una nueva Constitución pactada y por vías pacíficas o fruto de la violencia? ¿En dos o tres años, en diez, veinte o 
treinta? No lo sé. Únicamente confío en que cuando el momento llegue sea por la vía pacífica, que sea un proyecto pactado de Constitución entre las principales fuerzas políticas y que se someta a la consideración del electorado a través de un referendo.

Desde luego, ésta es una cuestión esencial, delicada y que amerita un análisis serio, objetivo y equilibrado. A ello me aboco.

2. ¿Por qué en el mundo, incluso en muchos de los países más estables en la actualidad, desde el ángulo político, social y económico, cambiaron sus Constituciones durante el siglo XX, en varias ocasiones? Las respuestas son diversas, debido a:

a) muchas naciones lograron su independencia, especialmente después de las dos guerras mundiales y durante las décadas de los años sesenta y setenta. Con posterioridad vivieron épocas de inestabilidad. Se pueden citar como ejemplos diversos países de África, ex colonias inglesas o francesas,

b) algunos países se desintegraron y de ellos se formaron, a su vez, varios Estados, como en el caso de la Unión Soviética, Yugoslavia y Checoslovaquia,

c) aconteció una ruptura profunda entre la antigua organización político-social y económica de la sociedad y la nueva organización, como en el caso de los países de Europa del Este después de la caída del muro de Berlín,

d) se efectuó una reorganización profunda respecto al poder en esa comunidad y sobre la forma de acceso al mismo, como es el paso de una monarquía a república o viceversa, el tránsito de un sistema presidencial a parlamentario o viceversa, o un sistema híbrido de gobierno; por ejemplo, la caída de las monarquías en los Balcanes, la Francia de 1958, o Japón, de una monarquía absoluta a una constitucional,

e) una catástrofe destruyó las bases constitucionales del Estado, como puede ser la participación en una guerra y más si pierde, como Alemania e Italia después de la segunda guerra mundial,

f) la ruptura o el restablecimiento del orden jurídico a través de una revolución, movimiento armado, golpe de Estado, pacto o referendo. Esa ruptura no tiene que ser necesariamente violenta, 
las hay pacíficas, como la que se pacta entre las principales fuerzas políticas y sociales del país. En América Latina los ejemplos abundan,

g) el tránsito de un gobierno de hecho o autocrático a uno constitucional-democrático, o viceversa, como en el caso de los gobiernos militares o las dictaduras civiles; así en la España de Franco o en las dictaduras de Argentina, Bolivia y Brasil,

h) por el peligro de caer en ingobernabilidad, ya sea porque la ingeniería constitucional se encuentra muy deteriorada y las instituciones desgastadas, y la propia marcha normal de los procesos políticos se realiza con enorme dificultad, como Colombia en 1991.

O sea, el cambio de una nueva Constitución a otra se impone, en virtud de que existe, por las más diversas causas, una profunda ruptura política y social, y resulta imperativo volver a organizar los mecanismos del poder en esa comunidad. Desde luego que la nueva organización puede y debe ser pactada.

¿Por qué Constituciones como la norteamericana o la inglesa, que son centenarias, continúan vigentes?; porque ha existido continuidad en sus procesos políticos con los cambios correspondientes, generalmente profundos, que les han proporcionado estabilidad política y social.

Algunos de los países europeos más importantes, que hoy en día gozan de un sistema democrático avanzado y de estabilidad política, durante el siglo XX cambiaron incluso varias veces de Constitución, precisamente porque se dio esa ruptura a la cual me he referido. Como ejemplos, recuerdo: Alemania comenzó el siglo como un imperio autocrático, después siguió la república de Weimar, el tercer Reich, la ocupación militar del país, la división en dos países y, finalmente su unificación.

Rusia inició ese siglo como un imperio también autocrático, al que le siguió un gobierno republicano de corte liberal, enseguida uno comunista - dictadura del proletariado - y pasó a formar parte de una gran federación centralizada - la Unión Soviética-, desintegración de esa Federación y establecimiento de un sistema híbrido presidencial-parlamentario con reconocimiento de la propiedad privada.

Francia empezó el siglo con una Constitución parlamentaria que propició una gran inestabilidad política; después de la ocupación alemana en la 
segunda guerra mundial y del régimen de Vichy se otorgó una Constitución que la llevó a un régimen asambleísta, también con marcada inestabilidad política, que fue la causa principal del actual sistema semipresidencial de gobierno con la Constitución de 1958.

España comenzó el siglo con una monarquía constitucional en crisis y con periodos autoritarios; después la segunda república, la dictadura y, actualmente, se configura una monarquía constitucional parlamentaria.

¿Por qué, entonces, y dentro de ese panorama de inestabilidad, la Constitución mexicana de 1917 ha sido tan longeva? Porque en estas casi diez décadas no se ha dado una ruptura político-social en nuestro país, porque su estructura fundamental mayormente ha sido aceptada por la sociedad, aunque sea en forma vaga, porque ha sabido evolucionar y cambiar a través de las reformas constitucionales a pesar de todos los errores y los excesos cometidos, porque durante décadas gozó de la legitimidad proveniente de la llamada Revolución mexicana, y porque impulsó paz y movilidad sociales con algunos lustros de crecimiento económico que, por desgracia, en los últimos treinta años se han convertido en reiteradas crisis económicas. Siempre existen razones y causas claras, positivas o negativas, de la longevidad o de la duración corta de una Constitución.

3. En los últimos seis lustros México se ha transformado, y no siempre para bien, ya que esas recurrentes crisis económicas han empobrecido a la gran mayoría de los mexicanos; muchos de los indicadores sociales han retrocedido y problemas de toda índole se han venido acumulando. ${ }^{1}$ No obstante, en el área política han acontecido aspectos positivos.

Sin embargo, las crisis económicas, los grandes rezagos sociales, los problemas acumulados, la inseguridad tremenda a partir de 2006, el desequilibrio entre los poderes durante casi setenta años, la sensación de que el sistema político se modifica con lentitud y no acaba de sacudirse de sus rasgos autoritarios y la idea de que una nueva Constitución podría canalizar el inmenso y creciente descontento y desasosiego sociales, han impulsado a políticos y a académicos a proponer diversos cambios constitucionales con la finalidad de propiciar un aceleramiento en el perfeccionamiento de nues-

1 Carpizo, Jorge, "Problemas acumulados”, Nexos, México, núm. 254, 1999, pp. $18 \mathrm{y}$ 19. Ensayo incorporado al libro, Temas constitucionales, México, Porrúa- UNAM, 2003, pp. 525-530. A partir de entonces, los problemas enunciados no se han resuelto; al contrario, se han agravado y han surgido otros nuevos. 
tro sistema democrático $\mathrm{y}$, dentro de este esquema, se escuchan voces que consideran que ha llegado el momento de transitar a una nueva Constitución.

Dentro de ese amplio marco de referencia, en la discusión del tema se pueden encontrar tres grandes corrientes de pensamiento:

a) No es necesario, menos indispensable, continuar reformando la Constitución,

b) Existen razones para crear una nueva Constitución, y

c) Ciertamente la Constitución necesita cambios y adecuaciones para perfeccionarla, y hay que hacerlos, pero, cuando menos por ahora, existen más inconvenientes que ventajas en su sustitución por una nueva.

Examino esas posturas.

\section{TESIS QUE SOSTIENEN QUE NO ES NECESARIO CONTINUAR REFORMANDO LA CONSTITUCIÓN}

4. Enuncio algunas de las principales tesis que sostienen que no es indispensable continuar reformando la Constitución:

a) Carla Huerta sostiene que la reforma constitucional se ha trivializado en las últimas décadas y que se quiere superar cualquier desajuste funcional con una reforma constitucional. El tema específico que está estudiando son los diversos medios jurídicos de control entre los poderes - tema muy importante-,y al respecto concluye que: "no es necesario seguir reformando la Constitución para precisar sus supuestos o adicionar nuevas formas de control, sino que se debe obligar a la autoridad a cumplir con sus deberes constitucionales, para hacer eficaz la Constitución", que esos controles comienzan a funcionar, aunque aún no posean eficacia plena, lo cual se debe a razones extrajurídicas que no se superan con reformas ya que "Las respuestas a la falta de ejercicio de las funciones de control son más bien de orden político, que consecuencia de un deficiente diseño institucional".2

b) José Ramón Cossío, más que oponerse a nuevas reformas constitucionales - la finalidad de su artículo es muy diferente al problema que

2 Huerta Ochoa, Carla, Mecanismos constitucionales para el control del poder político, México, UNAM-Instituto de Investigaciones Jurídicas, 1998, pp. 11-13, 152-153, 176-181. 
analizo-, realiza un repaso de los temas que diversas fuerzas políticas desean discutir y hace una advertencia respecto a los cambios constitucionales que es muy oportuna, y que en alguna forma coincide con la aguda observación de Carla Huerta con la cual estoy de acuerdo: el gran problema de nuestra Constitución no son las instituciones y protecciones que contiene, sino su cumplimiento real que se deforma por factores extrajurídicos en los que no influyen las reformas constitucionales; él destaca el elemento de la corrupción.

Cossío escribió que:

En el pasado, y dicho sencillamente, hemos transitado del régimen dictatorial de Díaz al de los revolucionarios, de éste al socialista de Cárdenas, de ahí al de los desarrollistas para luego pasar a los populistas, y de este último al de los tecnócratas. En cada caso, y en diversas ocasiones con reforma constitucional de por medio, se anunciaron una serie de cambios que, de un lado, permitirían la superación del pasado y, del otro, permitirían alcanzar de una buena vez, mejores condiciones sociales. En retrospectiva, se conocen los fracasos de esos intentos y, lo que aquí es más importante, los enormes niveles de corrupción que se suscitaron en cada una de esas modalidades de la historia nacional... Frente a una etapa deseable, no está de más el que nos advirtamos acerca de los peligros que encierra el permitir que las viejas prácticas de la corrupción puedan llegarse a ejercer al amparo de las renovadas y esperanzadoras formas de una etapa que aspira a ser democrática. ${ }^{3}$

A Huerta y a Cossío les asiste, en gran parte, la razón. Nuestros muy graves problemas no se originan en la Constitución, sino en prácticas metaconstitucionales, costumbres corruptas y un ambiente político, social y moral deteriorados y en crisis que impiden que las instituciones funcionen como la Ley Fundamental señala.

\section{TESIS QUE SOSTIENEN QUE DEBE CREARSE UNA NUEVA CONSTITUCIÓN}

5. Entre quienes sostienen la necesidad de crear una nueva Constitución, primordialmente encuentro a algunos líderes políticos de izquierda, quienes han expresado la conveniencia de tal posibilidad.

3 Cossío, José Ramón, “Cuestiones constitucionales. Transición democrática, régimen constitucional y corrupción”, Este País, México, diciembre de 1998; pp. 16 y 17. 
En la academia la idea también cuenta con defensores:

a) Jaime Cárdenas, en tres trabajos, ha señalado las razones por las cuales está a favor de una nueva Constitución, a saber:

- La Constitución de 1917 es obra del grupo vencedor; se necesita una nueva en que todos los grupos se vean reflejados, que sea el consenso de todas las fuerzas políticas,

- la Constitución ya no goza de legitimidad por los múltiples abusos a que ha sido sometida, a sus incontables reformas y a su diseño no-democrático,

- la Constitución no ha sido y no es "normativa", es decir, no regula el proceso del poder, ya que las reglas del juego político y social se encuentran fuera de ella, en factores metaconstitucionales,

- una nueva Constitución crearía una nueva legitimidad basada en la democracia pluralista de partidos,

- tanto las autoridades como los gobernados incurren en deslealtades constitucionales al dejar de aplicar preceptos constitucionales, o bien al rechazarlos,

- la Constitución no cuenta con la lealtad de todos los sectores del país, ya que no regula mecanismos ni instituciones para amplios grupos, como son los indígenas, organizaciones de la sociedad civil y los medios de comunicación,

— si se realiza a plenitud la "reforma del Estado", tantas modificaciones harían irreconocible a la ley fundamental,

- su articulado no produce certezas, sino genera confusiones,

- la nueva economía, la nueva política y las aspiraciones de las nuevas generaciones demandan un contrato social renovado,

- la ley fundamental no recoge los avances del constitucionalismo de la segunda posguerra ni los más recientes ${ }^{4}$ en el tiempo.

4 Cárdenas Gracia, Jaime, "Hacia una Constitución normativa", El significado actual de la Constitución, México, UNAM-Instituto de Investigaciones Jurídicas, 1998, pp. 106-108 y 117-118; del mismo autor, Transición política y reforma constitucional en México, México, UNAM-Instituto de Investigaciones Jurídicas, 1994, pp. 146-148 y 160; del mismo autor, Una Constitución para la democracia, México, UNAM-Instituto de Investigaciones Jurídicas, 1996, pp. 33-39.. 
Jaime Cárdenas realiza un interesante enunciado de los temas políticoconstitucionales que deben encontrarse en la agenda de la discusión; ${ }^{5}$ no obstante, no encuentro que justifiquen la creación de una nueva Constitución, tal y como posteriormente asiento.

b) Manuel González Oropeza también se encuentra a favor de una nueva Constitución. Sus principales argumentos son los siguientes:

- Las incontables y exageradas reformas que ha tenido la actual Constitución,

- el secretario de Gobernación de Carranza, Manuel Aguirre Berlanga, afirmó que una de las razones para convocar al Congreso Constituyente de 1916-1917 estribaba en la cantidad de reformas que había sufrido la Constitución de 1857, las cuales resultan pocas si se comparan con las que ha soportado la actual,

- los nuevos factores reales de poder, tales como los partidos políticos, el excesivo presidencialismo y el florecimiento de los derechos humanos hacen necesario una revisión integral de la Constitución,

- el presidente mexicano ha sido el único reformador de la Constitución, lo que ha traído como consecuencia reformas parciales, que la Constitución se haya convertido en un plan de gobierno para cada presidente y que éste haya fortalecido especialmente al Poder Ejecutivo. ${ }^{6}$

González Oropeza también presenta una lista de temas que considera necesario discutir dentro de una reforma integral de la Constitución. ${ }^{7}$

c) Otros argumentos expresados en favor de crear una nueva Constitución, son los siguientes:

- que incluye instituciones contradictorias,

- que el Estado debe ser "refundado" como una respuesta a las perspectivas políticas de renovación, como una forma de generar

5 Transición..., ibidem, pp. 162-188 y Una Constitución..., op. cit., pp. 43-58.

6 González Oropeza, Manuel, “Una nueva Constitución para México”, Memorias del VI Congreso Iberoamericano de Derecho Constitucional, Bogotá, Universidad Externado de Colombia, 1998, t. I, pp. 94-99.

7 Ibidem, pp. 100-104. 
confianza política y social de que ahora la reforma sí va en serio, ${ }^{8}$

- que la actual Constitución en esencia no es la misma que aque1la que fue promulgada en $1917 .{ }^{9}$

\section{TESIS QUE SOSTIENEN QUE DEBEN REALIZARSE REFORMAS, NO UNA NUEVA CONSTITUCIÓN}

6. Entre las principales tesis que sostienen que son necesarios cambios y adecuaciones constitucionales, pero no una nueva Constitución, menciono algunos de sus representantes más connotados, quienes en síntesis sostienen que la realidad constitucional de México ha cambiado aceleradamente en los últimos años, que los avances democráticos son muy importantes aunque aún insuficientes, que nuestra Constitución funciona hoy en día en forma diferente a los años anteriores, porque nuestros sistemas electoral y de partidos políticos son diversos de los que conocíamos y porque el fortalecimiento de los partidos políticos va cambiando el panorama del poder local y municipal, y en forma relevante el funcionamiento del propio Poder Legislativo federal. Dichos aspectos positivos impulsan las propuestas de reformas constitucionales para continuar perfeccionando nuestras instituciones políticas y nuestra democracia. ${ }^{10}$

Existe un grupo de constitucionalistas que considera que los cambios tienen que continuar, y que ellos son preferibles a emprender la titánica e impredecible labor de crear una nueva Constitución, labor en la cual se puede fracasar y, en lugar de seguir avanzando, se pueden dar pasos hacia atrás.

8 Serna de la Garza, José María, "El significado de la Constitución ante los procesos de transición democrática", El significado actual de la Constitución, México, UNAMInstituto de Investigaciones Jurídicas, 1998, pp. 541 y 542.

9 Hernández, María del Pilar, "Legitimidad constitucional, nueva Constitución y otros tópicos”, El significado actual de la Constitución, México, UNAM-Instituto de Investigaciones Jurídicas, 1998, p. 397.

${ }^{10}$ Entre otros se pueden citar a Lujambio, Alonso, Federalismo y Congreso en el cambio político de México, México, UNAM-Instituto de Investigaciones Jurídicas, 1995, pp. 94-105; Carrillo, Ulises y Lujambio, Alonso, "La incertidumbre constitucional. Gobierno dividido y aprobación presupuestal en la LVII Legislatura del congreso mexicano, 19972000”, Revista Mexicana de Sociología, México, vol. 60, núm. 2, 1998, p. 263. Vázquez Alfaro, José Luis, "Reforma del Estado Mexicano: Implicaciones Jurídico-Constitucionales”, El Mercado de Valores, México, año LVIII, 1998, pp. 47-52; Alcocer V., Jorge, "Antecedentes y perspectivas de la reforma del Estado en México", El Mercado de Valores, año LVIII, 1998, pp. 8-15. 
a) Ignacio Burgoa realiza una extensa propuesta de cambios constitucionales "para mejorarla (la ley fundamental) desde diferentes puntos de vista y adecuarla, en algunos preceptos esenciales, a las exigencias que reclama la evolución social, económica, política y cultural del pueblo mexicano". El distinguido maestro considera que no existe necesidad de sustituir nuestra actual Constitución por una nueva y, aun si tal no fuera el caso, no hay forma de sustituir válidamente nuestra carta magna sin la ruptura cruenta de la actual que sería fruto de un movimiento revolucionario o contrarrevolucionario, porque los poderes constituidos no pueden erigirse ni convocar a una asamblea constituyente en virtud de que no cuentan con facultades jurídicas al respecto. ${ }^{11}$

Considero que si en el futuro se requiriera de una nueva Constitución, no es necesario ni deseable el quiebre violento del orden constitucional actual; él sería la base misma de la nueva Constitución, al convocarse, después de un acuerdo - un pacto - entre las diversas fuerzas políticas del país, del comienzo de un procedimiento constitucional con la finalidad de construir una nueva Constitución. En forma bastante similar nació la actual Constitución de 1917 y el precedente es valioso. Así se han creado nuevas Constituciones en el derecho comparado y en países con cercanía constitucional al nuestro, como en algunas naciones de América Latina en los últimos treinta años.

b) Héctor Fix-Zamudio está en favor de cambios y reformas constitucionales, pero no de una nueva Constitución, porque:

- nuestra Constitución ha sido muy reformada, pero toda norma fundamental tiene que transformarse para responder a los graves problemas sociales de nuestra época,

- muchas de esas reformas han sido para incorporarle instituciones, principios y valores contenidos en las Constituciones más recientes, como en algunas de América Latina, por lo que puede considerarse que tenemos una Constitución "actual o contemporánea" o modernizada,

- ese cúmulo de reformas no ha creado una nueva Constitución, debido a que los principios importantes de la Constitución no son cerrados o inmutables ni representan una traición o una desviación

11 Burgoa, Ignacio, Renovación de la Constitución de 1917, México, Instituto Mexicano del Amparo, 1994, pp. 7-10. 
al pensamiento del Constituyente de Querétaro, sino una adaptación a las realidades actuales,

- la evolución de nuestra Constitución aún no ha concluido, será necesario seguir perfeccionándola en su trayecto hacia un sistema más pluralista y participativo. ${ }^{12}$

c) Diego Valadés está en favor de reformar la Constitución y no de crear una nueva; sus principales argumentos son los siguientes:

- existe la imposibilidad jurídica de convocar a una asamblea constituyente con fundamento en la actual Constitución,

- ¿realmente qué asuntos se persiguen resolver con una nueva Constitución que no se puedan superar a través de la reforma constitucional?, y ¿realmente cuáles son las instituciones que requieren ajustes?,

- los supuestos consensos constitucionales pueden llevar en sí los riesgos de los conflictos posteriores. En aras del "consenso" no se toma una decisión, sino se le delega al legislador ordinario,

- si no se llega a un consenso, como acontece en la actualidad, para reformar o "restaurar" la Constitución, mucho más difícil será alcanzarlo para crear una nueva,

- existen aspectos medulares de la Constitución que no necesitan una reformulación de los mismos - como los sociales en sus diversos ángulos-, sino que realmente se normativicen. ${ }^{13}$

Valadés, partidario entusiasta de la reforma constitucional, realiza un listado de los cambios constitucionales que propone para mejorar y perfeccionar nuestra ley fundamental. ${ }^{14}$

12 Fix-Zamudio, Héctor, "Constitución renovada o nueva Constitución”, Constitución Política de los Estados Unidos Mexicanos. 80 Aniversario. Homenaje, México, Senado de la República y UNAM, 1997, pp. 89-92, 94-97 y 110-113.

13 Valadés, Diego, "Todo cambio es constancia. Apuntes para una reforma institucional”, El significado actual de la Constitución, México, UNAM-Instituto de Investigaciones Jurídicas, 1998, pp. 561-567.

14 Ibidem, pp. 568-584; del mismo autor también consúltese, El control del poder, México, UNAM-Instituto de Investigaciones Jurídicas, 1998, pp. 404-410, 412-416 y 418, y "Problemas y Perspectivas de la Reforma del Estado", El Mercado de Valores, México, 1998, año LVIII, pp. 38-41. 
d) Salvador Valencia también se encuentra entre los juristas que se manifiestan a favor de la reforma constitucional y en contra de crear una nueva Constitución, porque:

- se rompería con una historia y tradiciones constitucionales que no son fáciles de encontrar en el mundo,

- a pesar de todas las reformas, subsisten en nuestra Constitución los principios políticos esenciales que la han configurado desde 1917 ,

- la Constitución nuestra es algo más que una ley fundamental, es el punto de unión y de confluencia de los mexicanos,

- debe revisarse el procedimiento mismo de la reforma constitucional para que el pueblo tenga una participación directa en el mismo. ${ }^{15}$

Salvador Valencia medita y expone las reformas constitucionales que deben llevarse a cabo en el México de nuestros días. ${ }^{16}$

e) Miguel Carbonell propone una reforma profunda e integral a la Constitución, ante los peligros de convocar a un Congreso Constituyente en la actualidad, cuando ha sido imposible lograr acuerdos sobre los contenidos posibles de una nueva Constitución. Este tratadista considera, entre otros aspectos, que el texto actual ha caído en la irrelevancia absoluta, que se plasman derechos que no sabemos como proteger, que sirvió al régimen político de un partido hegemónico y a un hiperpresidencialismo que hoy ya no existe, y que se corre el riesgo de que el proceso político nacional pudiera canalizarse a través de vías extrajurídicas. ${ }^{17}$

\section{LAS PERCEPCIONES SOCIALES SOBRE LA CONSTITUCIÓN}

7. Dentro del aspecto teórico y los criterios de los especialistas, no hay que descuidar las percepciones de la sociedad sobre la Constitución. En 2004 se publicaron los resultados de una encuesta efectuada el año anterior

15 Valencia Carmona, Salvador, Derecho constitucional mexicano a fin de siglo, México, Porrúa-UNAM, 1995, pp. 55-59.

16 Ibidem, pp. 50-54.

17 Carbonell, Miguel, Constitución, reforma constitucional y fuentes del derecho en México, México, Porrúa-UNAM, 2004, pp. 281-283. 
y patrocinada por instituciones de prestigio. Destaco algunos aspectos que otorgan datos valiosos de dicha percepción.

A la pregunta "Para usted ¿qué tan importante es la Constitución?", el $51.0 \%$ de los entrevistados contestó que muy importante; el $37.4 \%$ que importante; el $9.6 \%$ que poco importante; el 1.0\% que nada importante; el $0.5 \%$ no supo responder y el $0.5 \%$ no contestó. Es decir, el $88.4 \%$ tiene en alto valor a la ley fundamental.

A la pregunta "De las siguientes frases ¿cuál describe mejor a la Constitución?", el 36.2\% respondió que protege mis derechos; el $25.0 \%$ que organiza el gobierno; el $22.4 \%$ que no se respeta; el $9.7 \%$ que cambia a cada rato; el 2.6\% que no sirve para nada, y el 4.1\% eligió otra respuesta.

No obstante, existe gran desconocimiento de la Constitución. A la pregunta sobre cuánto se conocía esta norma suprema, el 72.6\% respondió que poco; el $20.3 \%$ que nada; el $4.8 \%$ que mucho; el 1.9\% no supo contestar; el $0.2 \%$ señaló otra opción, y el $0.2 \%$ no contestó. Los responsables de este trabajo hicieron unas consideraciones en relación con estos números:

...Estos porcentajes no sorprenden, ni deben considerarse necesariamente preocupantes. No sorprenden porque, según se señaló en los apartados iniciales, la regla en las sociedades modernas es el desconocimiento de las normas jurídicas. Podría aducirse, sin embargo, que el caso de la Constitución es diferente por tratarse de un ordenamiento fundamental que interesa a todos. Sin duda esto es así, pero como se deduce de numerosas preguntas que se han analizado en otros apartados, la población cuenta, en algunas áreas, con una conciencia y una cultura constitucionales visibles que constituyen una forma de conocimiento más profundo. Lo anterior no significa, claro está, que no deba hacerse mucho más por difundir y convertir en patrimonio de todos (por ejemplo, a través de la escuela), así como en tema de la discusión pública, los contenidos esenciales de la Constitución... (ésta), muy posiblemente, sea vista de forma genérica como un texto que debe respetarse y donde se afirman, o deberían afirmarse, leyes importantes para México y los mexicanos, pero no se conoce su contenido con mayor detalle.

Ante la pregunta sobre la necesidad de una nueva Constitución, el 40.1\% considera que hay que dejarla como está; el $23.3 \%$ que sí es preciso hacer una Constitución nueva; el 22\% que hay que cambiarla sólo en parte; el $10.0 \%$ no supo responder; el $2.4 \%$ contestó depende, y el 2.1\% señaló una opción diferente. 
Resulta interesante que únicamente el $4.7 \%$ estime que deben suprimirse las reformas introducidas a la Constitución. En consecuencia, no existe la percepción social de que la Constitución haya sido muy reformada o "parchada".

Desde otra perspectiva, con el paso del tiempo disminuye el porcentaje de quienes consideran que los cambios han sido demasiados, y aumenta, aunque tenuemente, quienes contestan que han sido muy pocos. El cuadro 17 de dicha encuesta así lo deja ver:

CuAdro 17. El gobierno cambió los artículos de la Constitución que tienen que ver con la educación, la Iglesia, el ejido y los requisitos para ser presidente. ¿Cree usted que estos cambios en la Constitución fueron demasiados o muy pocos? ${ }^{18}$

\begin{tabular}{|c|c|c|c|}
\hline \multicolumn{2}{|c|}{$\begin{array}{l}\text { La cultura de la Constitución } \\
\text { (2003) }\end{array}$} & \multicolumn{2}{|c|}{$\begin{array}{l}\text { Mexicanos de los noventa } \\
\text { (1994) }\end{array}$} \\
\hline Demasiados & $10.1 \%$ & Demasiados & $29 \%$ \\
\hline Muy pocos & $46.2 \%$ & Muy pocos & $43 \%$ \\
\hline Suficientes & $13.5 \%$ & Suficientes & $11 \%$ \\
\hline No debió haber & ambiado nada $9.7 \%$ & $\begin{array}{l}\text { No debió hab } \\
\text { nada } 3 \%\end{array}$ & biado \\
\hline Depende (esp) & $2.1 \%$ & NS-NC & $13 \%$ \\
\hline Otra (esp) & $0.5 \%$ & - & \\
\hline NS & $17.1 \%$ & - & \\
\hline $\mathrm{NC}$ & $0.7 \%$ & - & \\
\hline
\end{tabular}

18 Concha Cantú, Hugo A., Fix Fierro, Héctor, Flores, Julia y Valadés, Diego, Cultura de la Constitución en México. Una encuesta nacional de actitudes, percepciones y valores, México, UNAM-Instituto de Investigaciones Jurídicas-Tribunal Electoral del Poder Judicial de la Federación-Comisión Federal de Mejora Regulatoria, 2004, pp. 48 y 51-55. 


\section{FOROS PARA LAS MODIFICACIONES CONSTITUCIONALES}

8. Parece que la mayoría de los constitucionalistas mexicanos - cuando menos hasta ahora - se inclina por continuar reformando nuestra Constitución de 1917 para perfeccionarla, para lograr primordialmente un mejor equilibrio de los poderes públicos, una gobernabilidad dentro de la nueva realidad política y una mayor participación ciudadana en los asuntos de la república.

Tal vez se aproximen tiempos de profundos cambios constitucionales, si las fuerzas políticas se ponen de acuerdo, lo cual actualmente no es obvio. En este panorama es indispensable tener presente las ideas de José Ramón Cossío y de Carla Huerta ya mencionadas: prudencia en los cambios, realizar los que realmente sean necesarios y no pensar que con esos cambios se han resuelto los problemas. No hay que adjudicarle a la Constitución efectos mágicos o de "sanalotodo".

Las propuestas de cambios necesitan de una visión general del Estado mexicano, una gran dosis de pragmatismo y experiencia políticas, conocimiento profundo de nuestra evolución política, del derecho y la ciencia política comparados.

Ante la tormenta de cambios a nivel mundial, Sartori escribió que respecto a las cuestiones institucionales la pregunta esencial es: ¿sabemos qué reformar y cómo lo vamos a hacer? Su preocupación estriba en dilucidar si se conoce qué es lo que debe cambiarse y cómo cambiarlo, y contesta que no, lo cual ha tenido como consecuencia que "las reformas realizadas llevan la huella de reformadores muy incompetentes". ${ }^{19}$

Existen muchos ejemplos de cambios constitucionales recientes en el mundo y en América Latina; conocerlos es útil, aunque no existen fórmulas universales para lograr un cambio exitoso que combine bien democracia con gobernabilidad. Lo importante es el conocimiento profundo del país y de sus realidades histórica, política, jurídica, social y económica; tener un análisis preciso de las fallas del sistema y cómo se van a superar, al mismo tiempo que se refuerzan los valores del constitucionalismo liberal-filosófico y del constitucionalismo social, que actualmente deben ser inseparables entre sí.

Reformar una Constitución, más aún, crear una nueva, es algo en extremo delicado y en lo que se juegan aspectos esenciales de un país.

19 Sartori, Giovanni, Ingeniería constitucional comparada, México, Fondo de Cultura Económica, 1994, p. 12. 
En México ha estado de moda, desde 1998, hablar de la reforma del Estado para lo cual los especialistas y no especialistas - todos somos constitucionalistas, yo incluido - hemos propuesto una lista interminable de reformas, muchas de ellas sin meditación suficiente; a veces, las propuestas son de temas que se han escuchado, pero no se conocen con profundidad.

En no pocas ocasiones, esa "moda" ha arrastrado consigo a distinguidos tratadistas. En derecho constitucional, como en tantos aspectos de la existencia, las modas nos convierten en parte de Fuenteovejuna, de un frenesí colectivo, parecido a un festival de rock-and-roll, estrujante, ruidoso y difícil de escuchar. Todos somos parte del espectáculo.

Entonces, a partir de 1998, existen cuando menos tres ejercicios o consultas para realizar posibles reformas constitucionales o una modificación integral, enmarcadas en la denominada reforma del Estado.

La LVII Legislatura de la Cámara federal de Diputados convocó a foros regionales para que la sociedad se pronunciara sobre nuestra Constitución. En octubre de 1998 se publicaron los resultados, hasta aquel momento, de esos foros.

Se habían presentado 360 trabajos con 688 propuestas en relación a 120 artículos constitucionales. Las propuestas fueron de naturaleza muy diversa, desde la modificación de algunos artículos hasta la petición de no tocar otros, como el 16, 19, 22, 103, 107, 115, 123 y 135.

También se presentaron propuestas de carácter general en cuanto a estructura, sentido valorativo y análisis de nuestra ley fundamental.

Quince artículos constitucionales no fueron objeto de ninguna mención: el 32, 37, 68, 69, 77, 85, 86, 88, 91, 106, 112, 113, 118, 126 y 128.

Veintinueve ponentes se manifestaron a favor de crear una nueva Constitución y dieciséis se declararon en contra. ${ }^{20}$

Al término de ese ejercicio las ponencias presentadas sumaban más de 730 y los artículos constitucionales que se proponían reformar habían aumentado a 122 .

A partir de septiembre de 2000, se reunió la comisión de Estudios para la Reforma del Estado, que había sido instalada el anterior 21 de agosto por el entonces presidente electo Vicente Fox. Esa Comisión fue coordinada por Porfirio Muñoz Ledo; se formaron seis mesas de trabajo, subdivididas en cinco temas cada una, y participaron 167 ponentes.

20 Periódico El Universal, del 20 de octubre de 1998, primera sección, p. 21. 
El número de propuestas fue inmenso; en diversas ocasiones, las ponencias discreparon y no fue posible alcanzar consenso. La abundancia de las propuestas y la naturaleza tan amplia de las mismas implicarían no sólo la creación de una nueva Constitución, con grandes contradicciones entre sus normas, sino la refundación de la nación, y el programa de gobierno de varios sexenios. ${ }^{21}$

Dicho ejercicio no prosperó debido a que el presidente Fox designó a Muñoz Ledo como embajador de México ante la Unión Europea, con lo cual dio a entender que realmente no suscribía la labor de esa Comisión, la que él había aceptado, ni tenía confianza en el coordinador de la misma.

En marzo de 2001, la Secretaría de Gobernación convocó a un "Foro para la Revisión Integral de la Constitución", mismo que se subdividió en foros o grandes temas, los que, a su vez, se desarrollaron en diversas mesas, durante seis meses.

Se celebraron 51 sesiones, tanto en la ciudad de México como en otras ciudades de la República, se presentaron 324 trabajos escritos. Se propusieron reformas o adiciones a 75 artículos constitucionales. Dichos foros se caracterizaron por haber gozado de amplia difusión en los medios de comunicación. ${ }^{22}$

"La reforma del Estado", durante el sexenio de Fox, resultó en mucho ruido y ninguna nuez, aunque sí se prestó a situaciones increíbles. Únicamente, como ejemplo, señalo que cuando parecía que al fin se iba a conseguir la reelección de los legisladores, hubo marcha atrás. El Senado, en febrero de 2005, por la diferencia de un voto, y una abstinencia, decidió suspender la discusión del dictamen favorable y que éste regresara a las comisiones respectivas, donde permanece congelado. La escuela gatopardista al cuadrado.

La campaña electoral de 2006 parecía momento propicio para resucitar la idea de la tan traída reforma del Estado, más que Porfirio Muñoz Ledo volvió a estar cerca de uno de los tres candidatos presidenciales más importantes. No obstante, la campaña presidencial de 2006 se caracterizó por la escasez de propuestas.

21 Muñoz Ledo, Porfirio (coord.), Comisión de Estudios para la reforma del Estado. Conclusiones y propuestas, México, UNAM, 2004.

22 Agradezco al doctor Francisco Valdés Ugalde la amplia información que me proporcionó respecto al desarrollo de esos foros, contenida en un CD. El doctor Valdés Ugalde fue el responsable de la organización de aquéllos, en su carácter de director del Instituto Nacional de Estudios Históricos de la Revolución Mexicana. 
En consecuencia, algunas reformas constituyen aún materia pendiente. El último paquete muy importante de renovación constitucional en México aconteció en 1996. A partir de entonces no se ha perdido el tiempo; ha servido para que las ideas se depuren y las propuestas se ponderen y mediten con más cuidado, y algunos tratadistas se aparten del torbellino de propuestas a la ligera.

\section{MI CRITERIO Y MIS ARGUMENTOS}

9. Es hora de que exponga mi criterio personal.

A. Nuestra actual Constitución de 1917 amerita algunas reformas de fondo para resolver varios de los gravísimos problemas que aquejan a nuestro país desde hace cuando menos quince años y que en lugar de ser superados, se agravan. Me inclino porque el primer aspecto del cambio constitucional en esta etapa sea respecto al procedimiento de reforma constitucional para que una nueva Constitución, cuando llegue el caso, y las reformas constitucionales sólo puedan realizarse a través de referendo. Yo mismo he meditado sobre esta cuestión de las reformas constitucionales necesarias en diversas ocasiones y he formulado propuestas. ${ }^{23}$

B. En la actualidad, 2010, estoy en contra de que se pudiera crear una nueva Constitución por las siguientes razones:

a) La creación de una nueva Constitución no es un ejercicio teórico, no es una discusión académica, no es la expresión de buenos deseos o intenciones. Se crea una nueva Constitución cuando existe una ruptura - pactada o no- del orden jurídico, lo cual es un dato del mundo del ser, de la realidad y no del deber ser. Esa ruptura acontece, porque la Constitución ya no rige jurídicamente a la sociedad, porque existe ingobernabilidad o por algunas de las otras causas de ruptura - pactadas o no- que expuse en párrafos anteriores. El dato a retener es que una nueva Constitución se crea, más allá de que se quiera o no, cuando así tiene que acontecer ante la ruptura del orden jurídico.

23 Carpizo, Jorge, "La Presidencia renovada", Nexos, México, septiembre de 1998, p. 15; ensayo que se incorporó al libro, Temas constitucionales..., cit., pp. 525-530. Una propuesta más precisa, con los argumentos consiguientes se encuentra en Concepto de democracia y sistema de gobierno en América Latina, México, UNAM-Instituto de Investigaciones Jurídicas, 2007, pp. 137-171. 
En nuestros días existen problemas muy graves y serios en México, pero no hay ruptura - pactada o no- del orden jurídico, sino nuestra Constitución se actualiza todos los días; existen evolución y continuidad constitucionales.

b) La Constitución ha sido muy reformada, pero muchas de las reformas constitucionales han sido positivas, porque han introducido en la Constitución algunas de las instituciones más avanzadas del constitucionalismo de hace varias décadas y de nuestros días. Es decir, contamos con una Constitución moderna; no es una Constitución que se haya congelado y, por tanto, caducado; es una Constitución renovada.

c) Las Constituciones modernas son pactadas entre las fuerzas políticas y sociales más importantes de la nación. Se pacta el proyecto de Constitución para que ninguna de esas fuerzas se vaya a sentir excluida del pacto. En el México actual todo indica que es más fácil pactar un paquete de reformas constitucionales — si es que ello se logra - que pactar el contenido de toda una nueva Constitución. Hoy en día, los tres grandes partidos políticos difícilmente se ponen de acuerdo en aspectos importantes, incluso en aspectos menores les cuesta arduo trabajo llegar a acercamientos; ellos se encuentran a su vez muy divididos internamente, lo cual también dificulta los consensos. En muchas ocasiones, los partidos políticos están más preocupados por los aspectos inmediatos de la política que por el proyecto de nación a mediano y largo plazo.

d) Hay que luchar por ir resolviendo a la brevedad posible los más graves problemas que México tiene acumulados y no agregar otros, temas como el aborto, la planeación familiar, la eutanasia, el concepto de matrimonio y las relaciones Estado-iglesias son explosivos; respecto a ellos no se razona, se les envuelve en la emotividad, el fanatismo y la concepción ideológica. Pareciera difícil que los partidos políticos y fuerzas sociales discreparan civilizadamente en dichos temas en estos tiempos nuestros.

e) En muchos casos, al momento de discutirse y pactarse una nueva Constitución, no se logra el acuerdo y para superar esta situación se redacta una norma "borracha", que es muy ambigua o se delega al legislador ordinario la precisión de la institución; lo único que se hace es posponer el conflicto o para evitarlo se deja de legislar en esos aspectos, incluso por décadas.

f) El diseño institucional o la ingeniería constitucional de nuestra ley fundamental es adecuado: la base de las instituciones es el respeto de los derechos humanos, la noción de soberanía, república representativa y federal, separación de poderes y controles mutuos entre ellos, el laicismo de 
la vida civil y la existencia de garantías procesal-constitucionales adecuadas para la defensa de la propia Constitución. ¿En una nueva Constitución vamos a cambiar este diseño institucional? El mismo es perfectible, pero es el correcto.

g) Se atribuyen a la Constitución muchos de los males y vicios de la realidad política y social ¿en qué norma se basó la existencia de un partido predominante y que el jefe real de éste era el presidente de la República?, ¿en qué norma se basó el fraude electoral?, ¿en qué norma se fundamenta la corrupción y la impunidad que nos corroen?, ¿en qué norma se basó o auspició la destrucción de la moral pública, la virtud cívica y el patriotismo?

h) El presidencialismo mexicano que operó en la realidad es diverso del sistema presidencial que asienta nuestra Ley Fundamental; entre otras razones, porque no habían funcionado, y aún lo hacen tímidamente, los controles constitucionales que el Poder Legislativo puede y debe ejercer. Sólo hay que contemplar que en la nueva realidad política, el control constitucional de la cuenta pública continúa siendo casi inexistente.

i) Hay que saber con precisión qué queremos cambiar, por qué y cómo. Actualmente abundan las propuestas de cambio, algunas son adecuadas, otras decididamente no. En los cambios no hay que descuidar la cuestión de la gobernabilidad, debido a que si ésta no funciona adecuadamente se lesiona al propio sistema democrático, una de cuyas bases es precisamente la gobernabilidad.

j) Se pretende sustituir la Constitución cuando comienza, únicamente comienza, a funcionar como siempre debió de haberlo hecho: cuando los controles legislativos hacen sus pinitos, cuando los partidos políticos se han fortalecido y se ha creado un sistema tripartito de partidos, en lugar del hegemónico, cuando las elecciones gozan de alto índice de confiabilidad, cuando el pluralismo de la sociedad y su deseo creciente de participación política abre y fortalece diversas opciones políticas. La Constitución de 2010 , en su esencia, es gramaticalmente muy parecida a la de 2000, a la de 1995, 1990 o 1985, pero está operando en la realidad en forma diferente, y para bien, porque esa realidad política mexicana se ha alterado, aunque aún no se norma en su totalidad. El problema no ha sido ni es la norma constitucional, sino las prácticas y costumbres políticas viciadas y que mayormente se aceptaban sin cuestionarlas, incluso por algunas de las personalidades y grupos que con posterioridad se inconformaron con ellas; antes, ellos formaban parte de ese sistema. 
k) La tesis y el aspecto más importante de nuestra Constitución es el de la justicia social. En este asunto las propuestas de nuestra ley fundamental fueron y son de vanguardia. Lo que hay que lograr es que se normativicen íntegramente.

En esta específica cuestión se corre el peligro, en una nueva Constitución, de que se den pasos hacia atrás. Algunos de los países europeos con los niveles de vida más altos, están desmantelando diversos mecanismos de su Estado de bienestar con el pretexto o la realidad de que el Estado ya no cuenta con recursos económicos suficientes para mantenerlo tal y como se había establecido desde hace décadas.

El constitucionalismo social actualmente sufre verdaderos embates en contra. En México también; por ello, es indispensable que nuestra Constitución continúe siendo la mejor fortaleza de la justicia social. Hay que luchar, y con todas las fuerzas, por la normatividad plena de esos artículos constitucionales.

1) La Constitución tiene una legitimidad de décadas, es una síntesis de lo mejor de nuestra evolución jurídico-política. En una nación donde los mexicanos nos hemos venido dividiendo, no sería fácil ni rápido que una nueva Constitución se legitime. La actual, aunque en forma imprecisa en aspectos puntuales, es aceptada y apoyada por la mayoría de los mexicanos. Recordemos que el $88.4 \%$ de los encuestados contestó que para ellos es importante.

m) En muchas ocasiones el problema no es la norma, la reforma o la mutación constitucional que es la adecuada, sino que es un problema de personalidad, de ambiciones, mediocridades y frustraciones. En los últimos dieciocho años muchos nombramientos, sin que sea acertado generalizar, han sido un desastre; pareciera que mientras la estatura profesional, técnica, de carácter, de reconocimiento social, sea más pequeña, entonces es la persona idónea para ocupar la responsabilidad pública. Con posterioridad, los fracasos frecuentes se atribuyen a la Constitución o a la ley, y no al servidor público.

\section{REFORMAS URGENTES. SEIS PROPUESTAS}

10. Desde 2000 he venido sosteniendo que la moral pública en México se encuentra enferma o muy deteriorada, que el país está invadido de un cáncer agresivo representado en una "quinteta de la muerte" que se com- 
pone de poder arbitrario o irresponsable, dinero, corrupción, impunidad y mentiras, que los niños y los jóvenes han crecido viendo y sintiendo que esos elementos son algunas de las coordenadas centrales de la sociedad mexicana, que se puede ser un delincuente, pero si se tiene poder y dinero se gozará de impunidad, y se es un gran señor, aceptado y mimado por todos. Son los ejemplos que conocen y a eso aspiran: ser un señor con poder y dinero, sin importar cómo se obtengan, ya sea en la actividad política, los negocios, el crimen organizado, dirigencias de organizaciones sociales o religiosas. ${ }^{24}$

Estos gravísimos problemas no los crearon las normas constitucionales; al contrario, en gran parte, por su no aplicación. Se desprecia el Estado de derecho. Las violaciones constitucionales y legales no se castigan, y en muchos casos se festejan. Esta problemática no se supera con una nueva Constitución, sino con la aplicación de la vigente. Es un problema de la realidad, del ambiente cultural, de la pérdida de la virtud cívica, de la falta de voluntad política para aplicar la ley.

Con el actual marco constitucional y legal, si el mismo se hubiera aplicado, el país no se hubiera deteriorado al grado en que se encuentra en 2010. Los problemas crecieron y han debilitado al propio Estado en virtud de que, por irresponsabilidad, por corrupción, por incompetencia o por una combinación de ellas, la autoridad no cumplió con su deber. Incluso en la actualidad, dicho marco constitucional y legal sería suficiente para superar los problemas si se aplicara correctamente, sin distinciones ni excepciones. Los discursos y declaraciones sobran, lo que se necesita son acciones y más acciones dentro del marco legal.

Pero, ciertamente, se ha llegado a un extremo tal que reformas constitucionales puntuales y precisas, bien estructuradas, puedan agilizar la resolución de problemas como la corrupción, la impunidad y el poder irresponsable, si a ello se aúna voluntad política y los cargos son ocupados por las personas adecuadas. Enuncio las reformas que considero

${ }^{24}$ Carpizo, Jorge, Anatomía de perversidades. Reflexiones sobre la moral pública en México, México, Nuevo Siglo, Aguilar, 2000, pp. 82-92; del mismo autor, Gómez Gallardo, Perla y Villanueva, Ernesto, Moral pública y libertad de expresión, México, Jus, Res pública-Benemérita Universidad Autónoma de Puebla y Fundación para la Libertad de Expresión, 2008, pp. 9-33; del mismo autor, "La moral pública en México", Voz y voto, México, 2008, núm. 181, pp. 38-45. 
prioritarias, sin desarrollarlas, lo que he realizado en relación con algunas de ellas en otras ocasiones:

a) Transformar las procuradurías de justicia - las dependencias ministeriales - en verdaderos órganos constitucionales autónomos, cuyos ejes serían: adecuado nombramiento de los procuradores; la creación de los Consejos del ministerio público y los de la policía de investigación. Las garantías a esos agentes de una verdadera carrera; la autonomía presupuestal; la autonomía técnica de los fiscales y el juez de control especializado en la averiguación previa. ${ }^{25}$ Esta propuesta sería útil en la lucha contra la corrupción, la impunidad, la inseguridad pública, el ejercicio de la acción penal por razones políticas o "de Estado", y contra injusticias, especialmente para los que tienen menos recursos para defenderse.

b) Transformar los órganos fiscalizadores, como la Auditoría Superior de la Federación y sus análogos en las entidades federativas y en el Distrito Federal, en verdaderos órganos constitucionales autónomos; es decir, que no dependan de ninguno de los tres poderes públicos, pero que sean responsables de sus actos. Hay que fortalecer sus facultades para que su labor tenga consecuencias legales, incluso otorgándoseles la facultad del ejercicio de la acción penal como atribución propia en el campo de su competencia. ${ }^{26}$ Esta propuesta sería útil en la lucha contra la irresponsabilidad de los servidores públicos y la de todo aquel que reciba recursos públicos para su manejo, contra la corrupción, la impunidad y el desasosiego social que causa el saqueo de los bienes públicos.

c) Convertir a los institutos de acceso a la información pública en órganos constitucionales autónomos con facultades suficientes para que cumplan

25 Carpizo, Jorge, El expediente Posadas a través de la lupa jurídica. Averno de impunidades, México, UNAM-Instituto de Investigaciones Jurídicas, 2004, pp. 357-374; del mismo autor, Propuestas sobre el Ministerio Público y la función de investigación de la Suprema Corte, México, Porrúa-Instituto Mexicano de Derecho Procesal Constitucional, 2005, pp. 30-49.

${ }^{26}$ Carpizo, Jorge, Moral pública..., cit., p. 32; del mismo autor, CD del "Seminario Autonomía Constitucional de la Auditoría Superior de la Federación", con la ponencia ¿Por qué la entidad de Fiscalización Superior de la Federación debe ser un órgano constitucional autónomo?, México, UNAM-Instituto de Investigaciones Jurídicas, 2009; La autonomía constitucional de la Auditoría Superior de la Federación, Ackerman, John M. y Astudillo, César (coords.), México, UNAM-Instituto de Investigaciones Jurídicas, 2009. 
sus funciones. ${ }^{27}$ Esta propuesta ayudaría en la lucha contra la corrupción, la impunidad, la secrecía de los asuntos públicos, la irresponsabilidad de los servidores públicos, el desconocimiento por parte de la sociedad del manejo de la res publica, a la vez que fortalecería la transparencia de las cuestiones públicas.

d) Real independencia técnica a la Comisión Federal de Telecomunicaciones, ampliando sus facultades, inclusive la de sancionar, y su campo de acción para que abarque realmente todo tipo de telecomunicaciones y de radiodifusión. ${ }^{28}$ Esta propuesta auspiciaría la competencia y la democratización de los medios, otorgar seguridad jurídica y certeza a los concesionarios, asegurándoles criterios de igualdad, imparcialidad y neutralidad tecnológica, así como el equilibrio entre la competencia del mercado y el interés público y social que debe existir en medios que influyen en la sociedad en forma decisiva.

e) Iniciativa popular y referendo para las reformas constitucionales, tema al que ya me he referido en varias otras ocasiones, ${ }^{29} \mathrm{y}$ tendría los beneficios que he señalado.

A este paquete de "urgencia", sólo le agregaría otra cuestión, que es para prever una situación que se puede presentar si el presidente de la República llegara a faltar por la razón que fuere y los mecanismos actuales de substitución —artículos 84 y 85 c.—,${ }^{30}$ en la realidad política actual del país, pudieran dejar ese cargo sin titular por algunos días o semanas, con

27 Véase Carpizo, Jorge, "Transparencia, acceso a la información y universidad pública autónoma", Cuestiones Constitucionales. Revista Mexicana de Derecho Constitucional, México, núm. 21, 2009, pp. 73-98.

28 Álvarez, Clara Luz, "La Comisión Federal de Telecomunicaciones, ¿autónoma o cautiva?", en Esteinou Madrid, Javier y Alva de la Selva, Alma Rosa (coords.), La "Ley Televisa" y la lucha por el poder en México, México, UNAM, 2009, pp. 321-333.

29 Carpizo, Jorge, "El sistema representativo en México", Revista Jurídica Veracruzana, Xalapa, t. XXIII, núm. 2, pp. 5-35; del mismo autor, "La reforma política mexicana en 1977", Los derechos de pueblo mexicano. México a través de sus Constituciones, 2a. ed., México, Cámara de Diputados-L Legislatura-Manuel Porrúa, 1979, t. XII, pp. 193 251.; "Algunas reflexiones sobre el poder constituyente", Estudios en homenaje al doctor Héctor Fix-Zamudio, México, UNAM-Instituto de Investigaciones Jurídicas, 1988, pp. 141-152. Estos tres ensayos se encuentran incorporados al libro Estudios constitucionales, México, Porrúa-UNAM, 2003, pp. 170-172, 390-391 y 573-574 respectivamente; Concepto de democracia y..., cit., pp. 158-160; El tribunal constitucional y sus límites, Lima, Grijley, 2009, pp. 109-116.

${ }^{30}$ Carpizo, Jorge, El presidencialismo mexicano, México, Siglo Veintiuno Editores, 2006, pp. 64-68. 
todos los graves inconvenientes y peligros del caso. En nuestra historia constitucional, la vicepresidencia ha sido nefasta. Los mecanismos de los artículos mencionados deben subsistir, únicamente se necesitaría adicionar que mientras se designe al presidente, ocupará interinamente el cargo el funcionario que señale la ley respectiva, la que podría hacer un orden prevalente, comenzando por el secretario de gobernación. El interino no podría realizar cambio alguno en el gabinete ni en los órganos públicos como los descentralizados. Por esta opción se inclinan varios constitucionalistas. Es sencilla y lógica. ${ }^{31}$

Ya en una etapa posterior, se discutirían otras reformas que se han propuesto, algunas convenientes y otras no, según mi criterio.

11. Ahora bien, a pesar de ser muy conocido, no puedo dejar de insistir en que instituciones correctamente estructuradas no funcionan bien si en los cargos directivos no se encuentran las personas idóneas. Cuando los servidores públicos son incompetentes, irresponsables, no comprometidos con su labor o corruptos, o una combinación de algunos o todos estos aspectos, las mejores instituciones se encaminan ineludiblemente al fracaso, el cual puede ser de proporciones mayores, si además se aúnan estructuras constitucionales mal o débilmente concebidas.

La situación anterior resulta más complicada si se inscribe en un clima social de desprecio al Estado de derecho, de tolerancia a la corrupción, de impunidad, de pérdida de valores éticos laicos, de cinismo y de mentiras.

Por todo lo anteriormente expresado, más allá de discutir la posibilidad de una nueva Constitución o una reforma integral de la misma, es indispensable y urge crear una ética política que sea factor determinante para que el proceso político se conduzca dentro de los marcos que señala la Constitución, lo que ésta no autoriza no se deba realizar; es preciso fomentar la cultura de que nadie se encuentra por encima de la ley, que los cargos políticos y públicos son para servir a la comunidad y no, por ningún motivo, para la satisfacción o el enriquecimiento personales. Para actualizar lo anterior nada es más importante que los ejemplos, los actos, los hechos y las acciones dentro del marco de la ley.

31 Valadés, Diego, "La sustitución presidencial en México y en derecho comparado", Derecho constitucional. Memoria del Congreso Internacional de Culturas y Sistemas Jurídicos Comparados, México, UNAM, Instituto de Investigaciones Jurídicas, 2004, pp. 879-881. 
Hay que difundir más y cada día más el conocimiento de la Constitución y su importancia en la protección y defensa de los derechos de todas las personas, hay que fortalecer la cultura y la virtud cívicas, así como que el interés público y el bien común deben prevalecer sobre el de grupo o personal. En una palabra, hay que inculcar y hacer parte de nuestra cultura los valores del constitucionalismo como la mejor manera de realización colectiva e individual. 